\title{
'Solve for India, Solve for the World': Strategies of India to Lead with New Age Disruptive Technologies
}

\begin{abstract}
New age technologies like Blockchain, Artificial Intelligence, Data Analytics, Internet of Things, Cloud Computing, Data Analytics, also known as Industry 4.0 has become integral part of business organizations in developed countries. India along with other developing countries is also in the race to adopt these new disruptive technologies to bring in more efficiencies in the business processes. Though India was late to get into the 4IR wagon but it is trying hard to catch up with the major players globally. Establishment of Center for the Fourth Industrial Revolution, by World Economic Forum is a major achievement of the Government of India to catch up with the other countries globally, but there are several challenges which needs to addressed simultaneously, This paper focus on the level of adoption of these technologies in India, future prospects and the challenges being faced in successful adoption of these technologies.
\end{abstract}

Alka Maurya
Keywords: Industry 4.0, Blockchain, Artificial Intelligence, Data Analytics, Internet of Things, World Economic Forum

\section{INTRODUCTION}

According to World Economic Forum, $4^{\text {th }}$ Industrial Revolution (4IR) can be described as "cyber-physical systems" wherein both people and machines have new capabilities to the extent that technology has become integral part of our societies and even our human bodies (WEF, 2016).

To fully understand the term, Industry 4.0 one must go back to $18^{\text {th }}$ century when during the first industrial revolution, use of water and steam power lead to mechanization in factories, and goods were manufactured with machines and not with hands. Later during second industrial revolution, due to invention of electricity mass production and assembly lines was possible. Computer led automation was the face of third industrial revolution and in the current scenario, fourth Industrial Revolution is about interconnecting machines and devices in such a manner that they can take decisions without human involvement.

Revised Manuscript Received on July 22, 2019

Dr. Alka Maurya, HoD, International Business, Amity University, Uttar Pradesh \& Associate Professor, Amity International Business School
Thus 4IR is being viewed as a cyber-physical system, where man and machine in physical as well as cyber space will co-exist. Machines during 4IR are not only mechanized but are smart as well and will keep getting smarter as they get access to more data, thus making the factories more productive and efficient and less wasteful. In earlier revolutions capital was the key to success but in case of 4IR, talent, innovation and data will be the critical factor for success. It is believed that countries with high level to innovation and adoption of new technology will lead the wave of 4IR.

Fourth Industrial Revolution will bring cheers for manufacturers as it will help them in making the business processes more efficient due to large scale automation and will help in reducing the operating costs.

It also will be boon for consumers as they will be able to afford and access the digital world in real time from work, home or virtually anywhere. Due to large scale interconnectivity, it will be possible to remotely control all electronic devices on the move or at leisure, companies are manufacturing robots which are capable to doing household chores. Alexa and Siri are two very common examples where various tasks can be accomplished with just one command.

Though 4IR is a boon in most of the scenarios, it also its own set of disadvantages. Due to large-scale automation, there is fear of loss of jobs, especially in manufacturing sector where robots are replacing humans for routine tasks, workers with low-skill and low-pay are likely to loose their jobs. According to a research by KPMG, an Oxford study estimates that $47 \%$ of the jobs in the US, $69 \%$ of the jobs in India and $77 \%$ of the jobs in China will not exist in 25 years. Also, as these new technologies are getting integrated in business and also in our daily life, there is need for large pool of skilled workforce that can work on and work with these technologies and currently there is dearth of employees with required skill set. (Live Mint 2016).

Data analysis and data security and data localization are other issues which also needs to be addressed to harness the true potential of these new age technologies.

Global Industry 4.0 market is projected to reach US $\$ 214$ billion by 2023. Considering the growth and size of this industry both advanced and developing economies 
are embracing Industry 4.0 to increase their manufacturing competitiveness. On one hand most of the developed countries are concentrating on innovation and competitiveness, while on the other hand, developing countries like Malaysia, Thailand and Indonesia are implementing Industry 4.0 for efficient manufacturing. Countries have rolled out strategic initiatives to match pace with global industry 4.0 trend. For example, Japan launched the "Revitalisation Strategy 2016" to ensure growth in manufacturing sectors, "Singapore Smart Industry Readiness Index" aims at motivating companies to start, scale and sustain Industry 4.0 efforts in Singapore, "Made in China 2025" focus on enabling manufacturers prioritize Industry 4.0 in China.

Over the years technologies like Internet of Things (IoT), blockchain, 3D printing and artificial intelligence (AI), which are the main building blocks of Industry 4.0, have become part of our lives. These technologies have already been integrated in the business process and if properly harnessed they can bring in high level of efficiencies in our social systems as well. Trends in adoption of these technologies on global scale are as under:

- According to IoT Analytics the global market for Internet of Things grew 37\% from 2017 to \$151B in 2018. According to IDC, worldwide spending on the Internet of Things will grow at a rate of $13.6 \%$ to reach $\$ 1.2 \mathrm{~T}$ in 2022 , during the forecast period 2017-2022. According to a forecast by Ericcson the number of cellular IoT connections will reach $3.5 \mathrm{~B}$ in 2023, increasing at a CAGR of 30\% (Forbes, December 2018)

- According to a report by IBM, global blockchain market was worth $\$ 706$ million in 2017 and will reach $\$ 60$ billion by 2024. (WinterGreen Research 2018)

- DELOITTE Global predicts that sales related to $3 \mathrm{D}$ printing comprising of enterprise 3D printers, materials, and services-will surpass US\$2.7 billion in 2019 and will reach US\$3 billion in 2020. (Deloitte 2018). According to a report of IDC, The global spending on 3D printing was nearly USD 12 billion in 2018, an increase of 20 percent over 2017, and by 2021, IDC expects worldwide spending to be nearly USD 20 billion (Computer World, 2018). McKinsey believes that $3 \mathrm{D}$ printing market will be around, $\$ 100$ billion to $\$ 250$ billion by 2025 (Economic Times 2018).

- According to International Federation of robotics, annual supply of industrial robots increased was mere 60,000 units in 2009 is expected to increase to 630,000 in 2021. South Korea has the highest robot density of 631 robots per 10,000 individual, Singapore is at second position followed at Germany, Japan, US, UK and China. Largest number of robots are employed in the Automobile sector (Annexure Table 1).

\section{IR in India}

India is the second largest emerging economy after China. The Government of India has taken several policy initiatives like Make in India, Digital India, Start up India etc, to carve a niche for the country on the global map, still, India lags behind its global peers in adoption of 4IR. The country has started taking baby steps to improve productivity by adopting new age technologies to achieve the target set by the government to have $25 \%$ contribution in GDP of the country from manufacturing sector by 2022 .

Over the past few years, due many policy initiatives of the Government, India is able to improve its ranking in several Global Index. India is able to position itself as one of the country with focus on innovation and competitiveness. India's Global Innovation Index ranking has improved considerable since 2015. In 2017 it ranked 57 ${ }^{\text {th }}$ among 126 countries owing to its large pool of science and engineering graduates. (WEF October 2018)

Further, due to several initiatives of Government of India to make India a digital economy, there is considerable improvement in indicators like mobile phone and broadband subscriptions, internet bandwidth per user and internet access in schools etc. This helped India to achieve $40^{\text {th }}$ rank in the Global Competitiveness Report 2018. (WEF October 2018)

In its drive to imbibe Industry 4.0, Government has taken several initiatives in recent times, to provide the necessary infrastructure within the country to facilitate adoption of 4IR.

\section{Initiatives taken by Government to adopt industry 4.0}

\section{Center for the Fourth Industrial Revolution}

Most important step in this direction was the setting up of Center for the Fourth Industrial Revolution by World Economic forum. Though India was late to get into the 4IR wagon but it is trying hard to catch up with the major players globally. World Economic Forum realised the potential India has in the field of 4IR, and therefore it has set up Center for the Fourth Industrial Revolution, in Maharashtra in partnership with Government of India. Initial focus of the centre will be on projects in the field of drones, artificial intelligence and blockchain. NITI Aayog, business leaders, start-ups and academia will be part of this project of WEF. The Centre in India is fourth in the world after San Francisco, Tokyo and Beijing. (Times of India, 2018)

\section{Industrial Policy of Government of India}

New Industrial Policy of Government of India aims at aligning Government's

intention to integrate 
emerging technologies of drones, artificial intelligence and block chain in the business processes (Hindu Business Line, 2018).

\section{$\underline{\text { IoT Policy }}$}

To promote IoT ecosystem in the country, Department of Electronics and Information Technology, ( DeiTY) has come out with a draft IOT Policy document which focuses on following objectives:

- ensure that the industry should have around 5-6\% share of the global market and reaches 15 billion by 2020

- provide IoT specific skill-sets through capacity development program

- $\quad$ undertake Research \& development activities

- develop IoT products specific to Indian needs

\section{Make in India}

Make in India initiative was launched by the Government in 2014, since than lot of success have been achieved in pursuing the country's manufacturing agenda and global competitiveness. Globally, India is the sixth-largest manufacturing nation and the biggest recipient of foreign direct investments (FDIs), with inflows touching \$60 billion in 2016-17, the highest-ever annual inflow into the country. In fact it is been perceived that Make in India initiative is spearheading wider adoption of Industry 4.0.

\section{Smart Cities}

'Smart Cities Mission' of government of India, started in 2015 with the objective to build 100 smart cities across India, is being touted as the forerunners of the Industry 4.0 environment. The objective of the mission is to develop greener cities where smart solutions are applied in larger parts of the city. Smart cities will have immense potential for application of technologies like IoT, AI, Blockchain etc.

\section{Atal Innovation Mission}

In 2016, Government of India launched Atal Innovation Mission (AIM) with the objective to encourage and support innovation in the country. As part of the mission several state of the art Atal Tinkering Labs (ATLs) and Atal Incubation Centres (AIC) and Atal Community Innovation Centers (ACIC) have been established in schools, universities and industry to promote culture of innovation in the country. Atal New India Challenges (ANICs) are also organized from time to time to generate new ideas for product development in areas of national relevance and social importance. Considering the success of the mission Government approved expenditure upto Rs. 1000 crore till 2019-20 for expanding Atal Tinkering Labs to 10,000 schools. (NITI Ayog 2019)

\section{$\underline{\text { Startup India }}$}

Startup India initiative was launched in 2016. The initiative has been very successful in providing the entrepreneurial ecosystem in the country. According to NASSCOMZinnov report "Indian Start-up Ecosystem 2018: Approaching Escape Velocity", India ranked as 3rd biggest start-up hub in the world. The report also highlighted the fact that technology start-ups in the area of Data Analytics, AI and IoT increased by $50 \%$ from 2017, out of which start-ups in the area of Artificial Intelligence witnessed $120 \%$ growth in funding and received $\$ 150 \mathrm{mn}$ investment in 2018 alone. (NASSCOM-Zinnov 2018)

\section{Digital India Initiative}

Digital India laid the foundation for implementing Industry 4.0 in the country. Necessary infrastructure like mobile and broadband penetration has increased manifold over the years not only in the urban but also in the rural market.

\section{Future Prospects for 4IR in India}

According to the Prime Minister of India, Industry 4.0 is not a industrial or a digital transformation, but a social transformation, especially in country like India, where these technologies will immensely help in bringing irreversible positive changes.

President of World Economic Forum (WEF), is of the view that with more than 50 percent of the population in India is under the age of 27 and with such young and vibrant workforce India can play a major role in shaping the 4IR at a global level in a very responsible, scalable and inclusive manner. (Economic Times, April 2018). Another report of WEF reposed confidence that India can lead the world into the fourth industrial revolution stating "what works in India - with its inherent diversity, complexity and scale - will work in the world." (Dataquest, 2019)

PWC India's study published in 2016, highlighted that more than 80 percent of the manufacturing industry is expecting a greater than 10 percent improvement in efficiency, while over 60 percent of the surveyed respondents expect a 10 percent improvement in additional revenue. Industry 4.0 will also yield the benefit of a faster learning cycle and give an edge to Indian companies that are competing with legacy producers in Europe and the Americas, which have had a head start. (Forbes 2019)

Though India is not growing as fast as USA, China and other countries in the EU as far as 4IR is concerned but it has huge potential for the future growth. Current level of integration of these technologies in India are as under :

- IoT market in India will be around USD 15 billion, which will be around $5 \%$ of the global market. (Nasscom, 2016 )

- Big Data Analytics market was around 2 
billion USD in 2017 and is expected to grow at a CAGR of 26 percent reaching approximately USD 16 billion by 2025 , making India's share approximately 32 percent in the overall global market (Economic Times 2017)

- According to 6 Wresearch $3 \mathrm{D}$ printer market has grown rapidly in past few years and is expected to be around USD 79 million, by 2021 (Economic Times 2018).

- Robot penetration in India is very less with just 3 robots per 10,000 individual in 2016. Like other developed countries robots are primarily being used in Automobile companies. Though adoption of AI in India was late, but currently India is adopting AI at scale which is much ahead of the US (32\%), UK (35\%), and the global average $(36 \%)$. In 2010, to integrate industry 4.0 , Germany launched a national level strategic mission, with the aim to become a provider of advanced manufacturing solutions. In order to accomplish the mission the government focused on providing education and resources to small and medium enterprises and also collaborated with countries like China and Japan. On similar lines NITI Ayog, Government of India has also adopted a three-pronged approach whereby the focus is on (i) undertaking AI projects in various areas, (ii) collaborate with experts and stakeholders and (iii) craft a national strategy for building a vibrant $\mathrm{AI}$ ecosystem in India. It is expected that Artificial Intelligence (AI) is expected to more than double the rate of innovation and employee productivity in India by 2021

\section{Application of New Age Technology in India}

\section{Financial transparency through Blockchain}

According to a PwC's Global Fintech Survey, around 56\% of companies in Financial sector in India plan to adopt blockchain in their processes. These companies are of the view that in time to come this technology will have much wider application in payments/funds transfer infrastructure, digital identity management and post-trade settlements

\section{Drones}

To enable wider application of drones, Indian Directorate General for Civil Aviation issued first policy to permit commercial drone operations. The Government of India believes that through commercial use of drones especially in agriculture and healthcare sector they will be able to bring change in lives of around 1.3 million citizens in rural part of the country. Use of drone in agriculture will help the Government in providing precise information about crop yields, soil health, pest outbreaks and potential irrigation upgrades to farmers. Also using drones in healthcare sector will help in sending vaccines to remote areas as part of the public health campaigns if the Government.

\section{Addressing economic and social Issues through Artificial Intelligence}

Companies like Technologies like artificial intelligence will make it possible for the Government and companies to use volumes of data to their advantage. This will help the companies to offer differentiated services through hyperpersonalization, whereas by using this technology, Governments can address social challenges including food security in more efficient manner and work towards efficient use of energy and resources, thereby improving the standard of living and achieving sustainable growth.

Smart Factory by Boeing and IISC

\section{IR : Problems and challenges in India}

Though Industry 4.0 has multifold benefits, but to reap benefits from these technologies following issues have to addressed

\section{Lack of infrastructure}

To harness the potential of Industry 4.0 there is a need for fast telecommunication network. In India though the penetration rate of telecommunication services is high but the telecommunication network still suffers from low data speeds and unstable connection, which is a pre requisite for industry 4.0.

\section{Data Security and Data Privacy}

In addition to goods, lot of data is also produced as part of industry 4.0. Handling and ownership of these two assets is one of the major challenges, which the companies are facing. To unlock value from these assets, companies need solutions to make data easily accessible but in a very secure mode. Appropriate AI models are required to correlate data to augment human decision-making. There is need for a regulatory environment to address issues related to data privacy.

\section{Leaders with Digital Knowledge}

To successfully lead organization in industry 4.0 , there is a need of leaders who in addition to IQ, EQ, SQ should also have high level of DQ (Digital Quotient). To successfully embrace Industry 4.0 there is a need to leaders who can drive a culture of innovation and risk taking

\section{Up skilling talent}

It is being feared that Industry 4.0 will lead to loss of jobs for those who are involved in jobs that can easily be done by Robots. Therefore the concern right now is to upskill talent of workers especially in the areas of analytics and digital technologies, rather than replacing them. This will help in preparing workforce for the changing environment and also make them ready for future learning.

\section{Cost of Digital Technologies}


MSME plays a vital role in the manufacturing sector in India. It will be very difficult for these companies to build smart factories with interconnected system as they will not have necessary funds to do so.

\section{Cyber security}

In India, there is lot of skepticism as far as cyber security is concerned. According to India's Cybercrime Survey Report 2017 of KPMG , 79 per cent of corporations have acknowledged cyber security as one of the top-five business risks.

Table 1: Worldwide supply of Industrial Robots 2009-2017

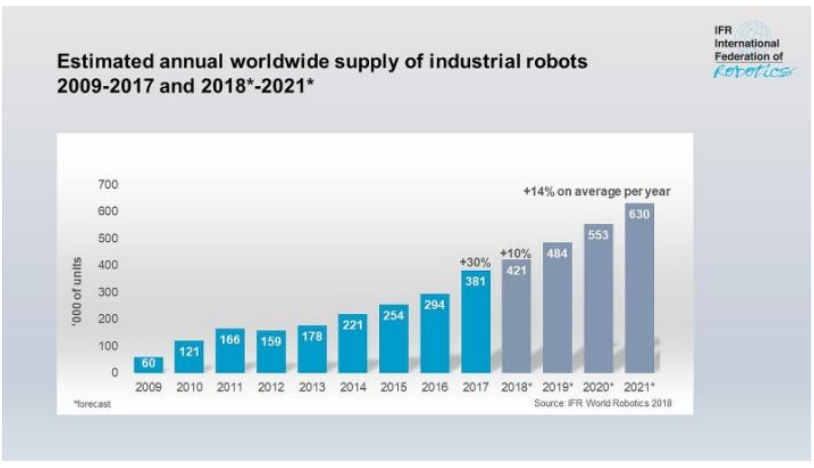

Source:International Federation of robotics,

https://ifr.org/downloads/press2018/Graph_total_annual_su pply_Industrial_robots_2009_2021.jpg

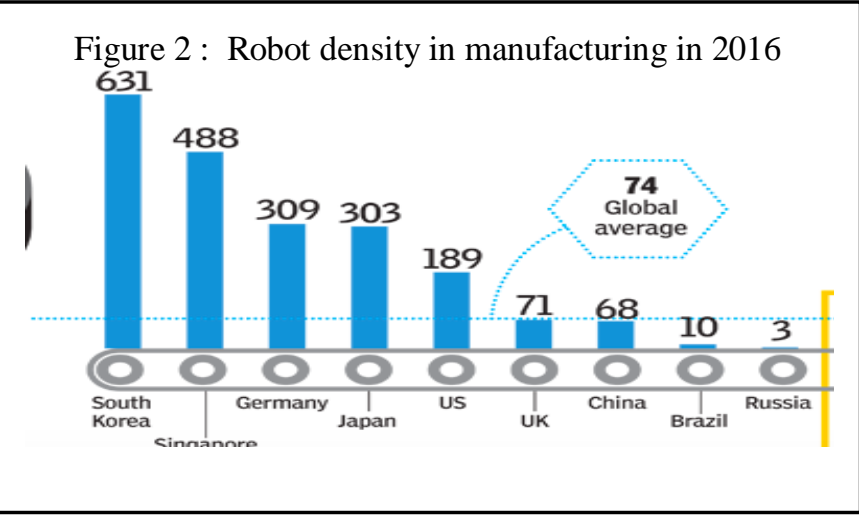

\section{Road Ahead}

India has the potential to become the digital factory of the world thereby having a solid footprint on the global map of digital manufacturing transformation as future India will be propelled by three powers -- next generation digital infrastructure, power of youth and power of the largest pool of next generation entrepreneurs.

Government is taking several initiatives to write a success story for India in Industry 4.0. Setting up R\&D facilities all the spheres of 4IR, faster telecommunication network, building a more conducive environment for data protection and security, backed by infrastructure to manage advanced targeted cyber-security threats and attacks, creating skilled workforce to take Industry 4.0 to next level, adequate support for MSMEs, standards-based interoperability and a conducive regulatory framework.

Government should also look at incentivizing companies which adopt digital technologies or are working towards developing the digital ecosystem, while meeting the requisite skill gaps and ensuring jobs for millions entering job markets.

Need of the hour is to ensure leveraging of the industry 4.0 revolution and reaping benefits of enhanced competitiveness for which collaborative efforts are required by central and state governments, industry, academia, research and financing institutions.

\section{REFERENCES}

1. What is the fourth industrial revolution?, (2016), Available at, https://www.weforum.org/agenda/2016/01/what-is-the-fourthindustrial-revolution/

2. Venkatesan Ravi, Is India ready for the fourth industrial revolution? Live Mint, (September 2016), Available at, https://www.livemint.com/Opinion/nWG88na6rgg72p07vV5tLN/IsIndia-ready-for-the-fourth-industrial-revolution.html

3. Shah Vijay, Industry 4.0: How India can build for the future, (2019), Available at, http://www.forbesindia.com/blog/technology/industry4-0-how-india-can-build-for-the-future/

4. Blockchain Market Shares, Market Strategies, and Market Forecasts, 2018 to 2024, WinterGreen Research, Inc., (2018), Available at, https://www.ibm.com/downloads/cas/PPRR983X

5. Stewart Duncan, 3D printing growth accelerates again, (December 2018), Available at, https://www2.deloitte.com/insights/us/en/industry/technology/techno logy-media-and-telecom-predictions/3d-printing-market.htm

6. Joshi Mansi, 3D printing in manufacturing: Where does India stand?, (April 2018), Available at, https://www.computerworld.in/feature/3d-printing-manufacturingwhere-does-india-stand

7. Prasad Rachita, 3D printing makes slow but steady inroads into industry, (June 2018), Available at, economictimes.indiatimes.com/articleshow/64706881.cms?utm_sour ce $=$ contentofinterest\&utm_medium $=$ text\&utm_campaign $=$ cppst

8. Executive Summary World Robotics 2018 Industrial Robots, Available https://ifr.org/downloads/press2018/Executive_Summary_WR_2018 Industrial_Robots.pdf

9. How India is harnessing technology to lead the Fourth Industrial Revolution, (October 2018), World Economic Forum, Available at

a. https://www.weforum.org/agenda/2018/10/how-india-is-harnessingtechnology-to-lead-the-fourth-industrial-revolution/

10. WEF launches Center for the Fourth Industrial Revolution in India, (October 2018), Times of India, Available at, https://timesofindia.indiatimes.com/business/india-business/weflaunches-centre-for-fourth-industrial-revolution-inindia/articleshow/66166216.cms

11. Incentives for green tech, AI likely in new industrial policy - The Hindu Business Line, 2018), Available at, https://www.thehindubusinessline.com/economy/incentives-forgreen-tech-ai-likely-in-new-industrial-policy/article22789065.ece

12. Ministry of Electronics and Information Technology, Available at, https://meity.gov.in/content/internet-things

13. Gaur Seema, Shaping the future of manufacturing in India, (July 2017), Available

https:/www.livemint.com/Opinion/mQqYAAL52lvVUqdIkeLTON/ Shaping-the-future-ofmanufacturing-in-India.html 
14. Smart Cities Mission, Available at, http://smartcities.gov.in/content/,

https://www.pwc.com/us/en/library/4ir-ready.html

15. Atal Innovation Mission, NITI Ayog, Available at, https://niti.gov.in/content/atal-innovation-mission-aim

16. Indian Tech start-up Ecosystem approaching escape velocity, (2018), NASSCON-Zinnov, Available https://www.nasscom.in/system/files/secure-pdf/Indian_Startup_Ecosystem_2018-Final_Report.pdf

17. India can play pivotal role in global fourth Industrial revolution, Economic Times, (April 2018), Available at, //economictimes.indiatimes.com/articleshow/63700143.cms?utm_so urce $=$ contentofinterest\&utm_medium=text\&utm_campaign=cppst

18. India can Lead the World into the Fourth Industrial Revolution: World Economic Forum, (February 2019), Available at, https://www.dqindia.com/india-can-lead-world-fourth-industrialrevolution-world-economic-forum/

19. IoT in India : Next Big Wave, (July 2016), NASSCOM, Available at, pdf/IoT in India report 05072016.pdf

20. Big data analytics to become $\$ 16$ billion industry by 2025 , (July 2017), Available

economictimes.indiatimes.com/articleshow/59410695.cms?utm_sour $\mathrm{ce}=$ contentofinterest\&utm_medium=text\&utm_campaign=cppst

21. What is Industry 4.0, why it offers huge opportunity for India? (2019), Available https://www.financialexpress.com/industry/what-is-industry-4-0why-it-offers-huge-opportunity-for-india/1452171/

22. Columbus Louis, 2018, Roundup Of Internet Of Things Forecasts And Market Estimates, (December 2018), Available at, Forbes https://www.forbes.com/sites/louiscolumbus/2018/12/13/2018roundup-of-internet-of-things-forecasts-and-marketestimates/\#32b3c4927d83

23. India can Lead the World into the Fourth Industrial Revolution: World Economic Forum, (February 2019), Available at, https://www.dqindia.com/india-can-lead-world-fourth-industrialrevolution-world-economic-forum/

24. Artificial Intelligence to double innovation rate in India by 2021: Study, (May 2019), Available at, economictimes.indiatimes.com/articleshow/69517220.cms?utm_sour ce $=$ contentofinterest\&utm_medium $=$ text\&utm_campaign $=$ cppst

25. Shah Mehul Lanvers, Industry 4.0 Could Make India A Global Leader In Manufacturing, (April 2015), Available at, Huffington Post, https://www.huffingtonpost.in/mehul-lanvers-shah/industry-40could-make-in_b_7030618.html

26. Kondratieva ksenia, Indian firms moving fast on road to Industry 4.0, Hindu Business Line, (February 2019), Available at, https://www.thehindubusinessline.com/economy/indian-firmsmoving-fast-on-road-to-industry-40/article26367177.ece

27. Garg Swati, Indian Technology Landscape Getting Stronger, Invest India, (May 2019), Available at, https://www.investindia.gov.in/team-india-blogs/indian-technologylandscape-getting-stronger

28. Embracing Industry 4.0 and Rediscovering Growth, Available at, https://www.bcg.com/en-in/capabilities/operations/embracingindustry-4.0-rediscovering-growth.aspx

29. Dewan Neha, In the race for AI supremacy, has India missed the bus?

(June

2019),

Available

at, https://economictimes.indiatimes.com/small-biz/startups/features/inthe-race-for-ai-supremacy-has-india-missed-the-

bus/articleshow/69836362.cms

30. Fourth Industrial Revolution: Is India prepared?, March 2018, Times of India, Available at, https://timesofindia.indiatimes.com/india/fourth-industrialrevolution-is-india-prepared/articleshow/63439642.cms

31. How can manufacturers embrace Industry 4.0?, Rolls Royce, Available at, https://www.rolls-royce.com/countrysites/india/discover/2018/industry-4-0-and-indianmanufacturing.aspx

32. Morgan Jacob, What Is The Fourth Industrial Revolution?, (February 2016), Available at, https://www.forbes.com/sites/jacobmorgan/2016/02/19/what-is-the4th-industrial-revolution/\#488c125df392

33. Kumar Arun M, What industry 4.0 means for corporation, February 2019, https://www.livemint.com/technology/tech-news/opinionwhat-industry-4-0-means-for-corporation-1550432348597.html

34. Maira Arun, The human side of 'Industry 4.0, (April 2019), Available at, https://www.thehindubusinessline.com/opinion/thehuman-side-of-industry-40/article26904618.ece

35. Jayakumar PB , Das Goutam, Embracing Industry 4.0, (February 2019), Available at, https://www.businesstoday.in/magazine/thehub/embracing-industry-40/story/311990.html

36. Marr Bernard, What is Industry 4.0? Here's A Super Easy Explanation For Anyone, (September 2018), Available at, https://www.forbes.com/sites/bernardmarr/2018/09/02/what-isindustry-4-0-heres-a-super-easy-explanation-foranyone/\#2c4e2b019788

37. National Strategy for Artificial Intelligence, (June 2018), Available https://niti.gov.in/writereaddata/files/document_publication/National Strategy-for-AI-Discussion-Paper.pdf

38. Maurya Alka, Sinha Abhay, IoT and Smart Cities, (March 2019), Synergy, Bangalore Chamber of Commerce and Industry, https://bcic.in/upload/pdf/Synergy\%20March\%202019\%20Web.pdf 